MS30-P20 Synthesis, structure and reactivity of $\left[\mathrm{Cu}(\text { phen })_{2}\right] \mathrm{BrO}_{2}$ aaerobic oxidation of $\mathrm{Br}^{-}$to $\mathrm{BrO}_{2}{ }^{-}$at room temperature

Shin-Guang Shyu ${ }^{1}$, Md.Munkir Hossain ${ }^{1}$, Chi-Rung Lee ${ }^{2}$, Mei-Chun Tseng ${ }^{1}$

1. Institute of Chemistry, Academia Sinica

2. Department of Chemical Engineering, Minghsin University of Science and Technology, Taiwan

email: sgshyu@gate.sinica.edu.tw

Unusual 4e 4 oxidation of $\mathrm{Br}^{-}$ion into a $\mathrm{BrO}_{2}^{-}$ion occurred during the reaction between $\mathrm{CuBr}^{2}$ and phenanthroline under air to form $\left[\mathrm{Cu}(\text { phen })_{2}\right] \mathrm{BrO}_{2}$ complex. ESI-MS of the compound confirm the presence of $\mathrm{BrO}_{2}^{-}$in the solution. Its oxidation reactivity is different from its analogue $\left[\mathrm{Cu}(\text { phen })_{2}\right] \mathrm{ClO}_{2}$

Keywords: Aerobic oxidation / Broride ion / Brorite ion / Copper
MS30-P21 The effect of weak interactions on the shape of cadmium(II) coordination polymers with pyridine-based hydrazines

Boris-Marko Kukovec ${ }^{1}$, Nikolina Penić1, Nives Matijaković ${ }^{1}$, Marijana Đaković ${ }^{1}$

1. Division of General and Inorganic Chemistry, Department of Chemistry, Faculty of Science, University of Zagreb, Horvatovac 102a, HR-10000 Zagreb, Croatia

email: bkukovec@chem.pmf.hr

Coordination polymers are infinite systems build up from metal ions and organic ligands (linkers) as the main units assembled via coordination bonds and weak interactions (hydrogen bonds, $\pi-\pi$ interactions, metal-metal interactions, metal-aromatic interactions) [1]. Coordination polymers can extend in one, two or three dimensions. The 1D motif can be represented by linear, zigzag, double, ladder-like chains or helices. 2D and 3D coordination polymers are often called metal-organic frameworks (MOF). These materials have been used in crystal engineering due to their structural diversity and their applications as porous materials, in catalysis, ion exchange and gas storage [2]. Coordination polymers can also have other interesting properties e. g. nonlinear optics, luminescence and magnetism. We have prepared a series of cadmium(II) coordination polymers with isoniazid and niazid and various counterions (chloride, bromide, iodide, thiocyanate). Isonicotinylhydrazine (isoniazid) and nicotinylhydrazine (niazid) are suitable linkers for construction of coordination polymers as they are multidentate ligands - $\mathrm{N}, \mathrm{O}$-bidentate and $\mathrm{N}$-bridging. They are capable of satisfying cadmium(II) coordination number (usually 5-7) by acting as $\mathrm{N}, \mathrm{O}$-bidentate ligands and they bridge the metal ions at the same time (via pyridine $\mathrm{N}$ atom). The aim of our study was to determine the effect of the counterions size, shape and their involvement in weak interactions on dimensionality of cadmium(II) polymers with isoniazid and niazid. In case of chloride and bromide use, we obtained 1D polymers with double chains, linked via chloride/bromide bridging atoms (Fig. 1a), while in case of iodide use, a 1D polymer with zigzag chain was formed, containing terminal iodide ions only. A 2D polymer was obtained by using thiocyanate ion, as it is an ambidentate ligand with $\mathrm{N}$ and $\mathrm{S}$ donor atoms, enabling the formation of a network (Fig. 1b). The polymers were also studied by IR spectroscopy, PXRD and thermal methods (TG/DTA, DSC) and various crystallization techniques were employed to get suitable single crystals for X-ray structure analysis.

References: [1] A. Y. Robin, K. M. Fromm, Coord. Chem. Rev. 250 (2006) 2127.; [2] U. Mueller, M. Schubert, F. Teich, H. Puetter, K. Schierle-Arndt, J. Pastré, J. Mater. Chem. 16 (2006) 626. 


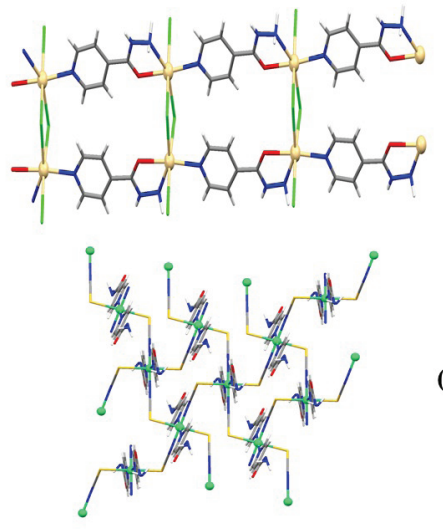

(a)

(b)

Figure 1. Cadmium(II) 1D coordination polymer with chloride and isoniazid (a) and 2D coordination polymer with thiocyanate and isoniazid (b)

Keywords: coordination polymer, cadmium, isoniazid, niazid, crystal structure, weak interactions

\section{MS30-P22 Structural, spectroscopic and activity studies of biomimetic resorcinarene-based zinc and copper complexes}

\author{
Aleksandar Višnjevac ${ }^{1}$, Jérôme Gout ${ }^{2}$, Olivia Bistri ${ }^{2}$, Olivia \\ Reinaud $^{2}$
}

1. Institut "Ruđer Bošković", Bijenička 54, 10000 Zagreb, Croatia 2. Université Paris Descartes, CNRS UMR 8601, 45, Rue des Saints Pères, F-75006 Paris, France

email: aleksandar.visnjevac@irb.hr

The syntheses, chemical characterizations, and activity studies of $\mathrm{Zn}(\mathrm{II}), \mathrm{Cu}(\mathrm{I})$ and $\mathrm{Cu}(\mathrm{II})$ "bowl" complexes, based on the resorcin[4]arene scaffold with three imidazole-containing coordinating arms at the large rim, is presented. These complexes are biomimetic models of a mononuclear active site where cofacial triade of amino-acid residues holds the metal coordinated. The trisimidazole ligand RIm3 was prepared in a seven-steps procedure. The complexes of $\mathrm{Zn}(\mathrm{II}), \mathrm{Cu}(\mathrm{I})$ and $\mathrm{Cu}(\mathrm{II})$ were prepared by simple reactions of the ligand with stoichiometric amounts of corresponding salts. Spectroscopic studies [and X-ray single crystal analysis in case of the $\mathrm{Cu}$ (II) acetato complex] revealed a 5-coordinate SBP environment for the $\mathrm{Zn}$ (II) and $\mathrm{Cu}(\mathrm{II})$ centres provided by three imidazole arms, and two extra donors, one embedded inside the resorcinarene cavity, the other in exo position. These two labile sites are occupied by solvent molecules or residual water, and are readily displaced by carboxylate donors, the position of which (endo or exo) is under tight control of the cavity. The reaction of RIm3 ligand with $\mathrm{Zn}$ (II) or $\mathrm{Cu}(\mathrm{II})$ acetates led to the formation of the acetatocomplexes with the acetate irreversibly embedded inside the cavity. The molecular structure of the $\mathrm{Cu}(\mathrm{II})$ acetato complex features a rigidified resorcinarene bowl. The isolated resorcinarene basket possess a non-crystallographic, $4 \mathrm{~mm}$ point symmetry, and can easily host small guest molecules. Three methylimidazole-containing coordinating arms at the large rim coordinate the $\mathrm{Cu}$ (II) ion. Its coordination sphere is completed by two $\mathrm{O}$ atoms from the intra-cavity bound acetate. The electron donors form a distorted square pyramide, where one of the nitrogens is at the appical position. The endo-coordination of the acetate is supported by an extensive network of intramolecular $\mathrm{C}-\mathrm{H} \cdots \mathrm{O}$ and $\mathrm{C}-\mathrm{H} \cdots \pi$ interactions. Complex crystallizes in $P 2 / c$ space group; $a=32.3310$ (4) $\AA, b=11.5490$ (1) $\AA$, $c$ $=21.6020$ (2) $\AA, \beta=102.281(3)^{\circ}$.

[1] Višnjevac, A; Gout, J; Ingert, N; Bistri, O; Reinaud, O, (2010) Org. Lett. 12, 2044 - 2047.

[2] Gout, J., Višnjevac, A., Rat, S., Bistri, O., Le Poul, N., Le Mest, Y. \& Reinaud, O. (2013) Eur. J. Inorg. Chem. $5171-5180$.

[3] Gout, J., Višnjevac, A., Rat, S., Parrot, A., Hessani, A., Bistri, O., Le Poul, N., Le Mest, Y. \& Reinaud, O. (2014) Inorg. Chem. 53, $6224-6234$. 